\title{
Assessment of the sustainability of the street network in Kaunas city
}

\author{
A. Guzys, J. Ilgakojyte-Bazariene \& J. Sapragonas \\ Department of Transport Engineering, Kaunas University of Technology, \\ Lithuania
}

\begin{abstract}
Infrastructural changes in the transport system of the city complicate the characteristics of travel time, traffic safety, air and noise pollution, living comfort, etc. The main causes could be formulated as follows - the actual infrastructure type and the street use are not compatible with a set of street functions, i.e. there are failures in the relations of function-form-use. The origin of this inadequacy is an old and wrongly developed street network, and improper combinations of street functions. The influence of infrastructural modifications on the characteristics of traffic flow were integrated. The model created describes the typical categories of streets, adequate complex functions and their relations. The conclusions show the possibility to apply this model to the evaluation of sustainability of changes in the urban street network.
\end{abstract}

Keywords: street network, function.

\section{Introduction}

Rapid economic development causes the growth of traffic volume on the major and minor streets of Kaunas city. Economic effects also contribute to the changes in the street infrastructure and in the distribution of road user flows: new commercial and residential zones, and new centres of attraction appear, which change the distribution of vehicle and pedestrian flows.

Roads are more or less described in the guidelines and standards of road design. However, the city's street network is planned not only according to official requirements but also certain realities and shortcomings (historically based street network, lack of funds, lack of knowledge, political and economic interests, etc.). 
From the traffic safety point of view we know a sustainable safety strategy, which is characterised as a proactive and preventive approach [1]. Sustainable safety recognises that $90 \%$ of road accidents could be attributed (to a greater or lesser extent) to human error. Consequently, sustainable safety realises that the humans are the weakest link in the road and transport chain. Furthermore, the individuals do not change or adapt themselves and many attempts to influence road user behaviour have failed or have had only short-term effects. The limitations of the individual remain evident [2]. Motivation, attention, emotion, observation, prediction, knowledge and skills are all weaknesses that prevent the humans from being the ideal traffic participants.

\section{Methods}

Sustainable safety is based on a system approach where all the elements of traffic safety and a transport system are geared to each other. Several levels of interaction were determined: the man-vehicle-infrastructure relation at the highest level and the relation between infrastructure-related characteristics at the next level (see fig. 1).

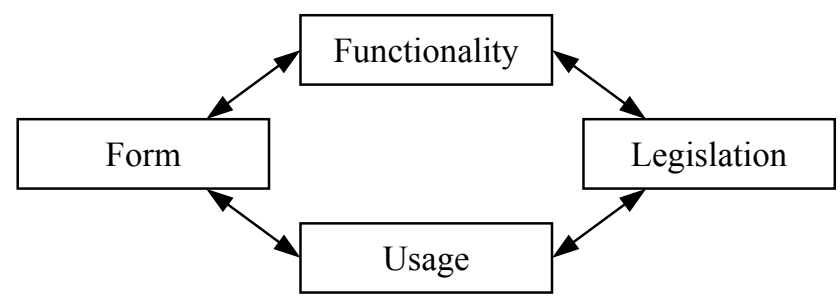

Figure 1: Functional relation model.

A general model of sustainable safety is formed according to these functional relations. An attempt was made to expand this functional relation model over the traffic safety issues and to obtain more complex and thorough evaluation of traffic processes and different impacts. Functionality represents the use of the infrastructure as intended by the road authority, Form the physical design and layout properties of the infrastructure, Legislation the regulatory requirements for the use of the infrastructure and Usage the actual use of the infrastructure and behaviour of the road user within the system. Functionality, form, legislation and usage are expressed as separate functions with a certain number of variables (see table 1).

The number of variables is not definite, depending on the complexity of the model and the modelling tasks. The origin of variables depends on the modelling goals and available data. The measured values of function variables can be applied in the model of the current situation. For modelling of an alternative situation or making prognosis the values of the variables $f_{i j}$ (here $i$ is the index of the function, $j$ is the index of the variable) can be determined by applying different methods and models. 
Table 1: Model functions and their variables.

\begin{tabular}{|c|c|c|c|}
\hline $\begin{array}{l}\text { FUNCTIONALITY } \\
\left(F_{1}\right)\end{array}$ & FORM $\left(F_{2}\right)$ & $\operatorname{USAGE}\left(F_{3}\right)$ & $\begin{array}{l}\text { LEGISLATION } \\
\left(F_{4}\right)\end{array}$ \\
\hline Through road $\left(f_{11}\right)$ & Cross section $\left(f_{21}\right)$ & Traffic volume $\left(f_{31}\right)$ & Traffic rules $\left(f_{41}\right)$ \\
\hline $\begin{array}{l}\text { Distributor road } \\
\left(f_{12}\right)\end{array}$ & Access control $\left(f_{22}\right)$ & Average speed $\left(f_{32}\right)$ & $\begin{array}{l}\text { Police } \\
\text { enforcement }\left(f_{42}\right)\end{array}$ \\
\hline Access road $\left(f_{13}\right)$ & $\begin{array}{l}\text { Type of } \\
\text { intersection }\left(f_{23}\right)\end{array}$ & $\begin{array}{l}\text { Fleet composition } \\
\left(f_{33}\right)\end{array}$ & $\cdots$ \\
\hline \multirow[t]{7}{*}{ Pedestrian road $\left(f_{14}\right)$} & $\begin{array}{l}\text { Density of } \\
\text { intersections }\left(f_{24}\right)\end{array}$ & $\begin{array}{l}\text { Volume of ped. \& } \\
\text { cyclists }\left(f_{34}\right)\end{array}$ & \\
\hline & Car parking $\left(f_{25}\right)$ & $\begin{array}{l}\text { Flow directions of } \\
\text { road users }\left(f_{35}\right)\end{array}$ & \\
\hline & Speed limit $\left(f_{26}\right)$ & 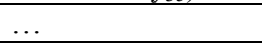 & \\
\hline & $\begin{array}{l}\text { Traffic calming } \\
\text { measures }\left(f_{27}\right)\end{array}$ & & \\
\hline & $\begin{array}{l}\text { Infrastructure for } \\
\text { ped. \& cyclists }\left(f_{28}\right)\end{array}$ & & \\
\hline & $\begin{array}{l}\text { Infrastructure for } \\
\text { public transport } \\
\left(f_{29}\right)\end{array}$ & & \\
\hline & $\ldots$ & & \\
\hline
\end{tabular}

Variables $f_{i j}$ can obtain different original values:

- $\quad$ the directly-measured (predicted) variables $\left(f_{31}, f_{32}\right.$, etc.);

- $\quad$ the variables of preset values $\left(f_{21}, f_{22}\right.$, etc.);

- $\quad$ the expert-evaluated variables $\left(f_{41}, f_{42}\right.$, etc.);

- $\quad$ the complex values $\left(f_{11}, f_{12}\right.$, etc.).

Functionality $F_{l}$ describes the "purpose" of the specific road:

- $\quad$ through road (arterial street) $f_{11}$ - for long distances and high speed;

- distributor road (collector street) $f_{12}$ - for shorter distances between through roads and access roads;

- $\quad$ access road (residential street) $f_{13}$ - to reach of private and public properties and for communication;

- $\quad$ pedestrian road $f_{14}$ - for pedestrians and cyclists (also a service road in rural area).

$F_{1}$ is characterised by the specific design, use and legislation of the road. Thus, the variables of $F_{1}$ are expressed as the arrays of variables of functions $F_{2}$, $F_{3}$ and $F_{4}$ with preset values $f_{1 i}=\left\{f_{2 i}, \ldots, f_{2 n}, f_{3 i}, \ldots, f_{3 n}, f_{4 i}, \ldots, f_{4 n}\right\}$. For example, the arterial street $\left(f_{11}\right)$ is planned to have a certain cross section $\left(f_{21}\right)$ according to a high speed limit $\left(f_{26}\right)$ and a large traffic volume $\left(f_{31}\right)$. The street can have specific-type intersections $\left(f_{23}\right)$, restrictions for car parking $\left(f_{25}\right)$, pedestrian/cyclist movements $\left(f_{35}\right)$, etc.

In practice there exist various intermediate values, thus, the final value 1 or 0 of $f_{1 \mathrm{i}}$ is under the decision of the experts. The interaction between the functions $F_{1} \ldots F_{4}$ describes the whole traffic process. It is considered that sustainability is achieved when values of $f_{1 i}$ correspond to the values of the variables of the 
functions $F_{2}, F_{3}, F_{4}$ and only one $f_{1 i}=1, i=1 \ldots 4$, othervise failure is determined.

\section{Results}

Traffic flows in the city centre were analysed by EMME/2 software to identify the high traffic volume or the congested links in the city centre and to apply the functional relation analysis. Figure 2 a shows the traffic volume in the Kaunas city street network.

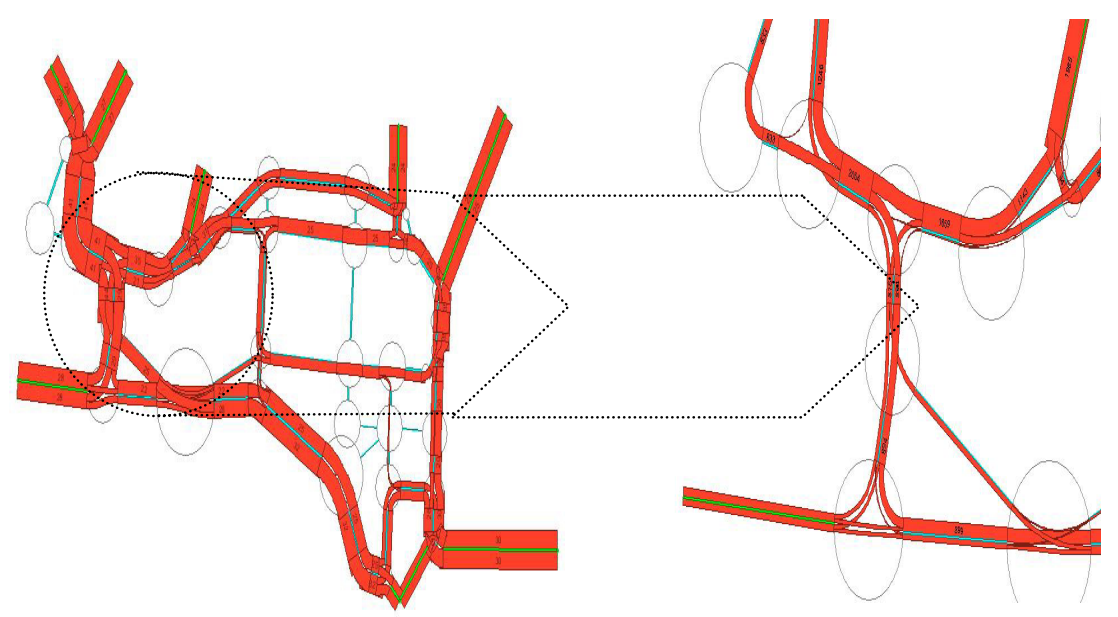

(a)

(b)

Figure 2: Traffic flows in the transport network of Kaunas centre (a) and detailed view of congested links (b).

Table 2: Results of linear regression analysis.

\begin{tabular}{|l|c|c|}
\hline Scenarios & $\begin{array}{l}\text { Regression } \\
\text { coefficient, } R\end{array}$ & $\begin{array}{l}\text { Standard deviation, } \\
\text { Std }\end{array}$ \\
\hline $\begin{array}{c}1-\text { transformed infrastructure of } \\
\text { the street network }\end{array}$ & 0.17900 & 1.352661 \\
\hline $2-$ existing street network & 0.33614 & 2.443941 \\
\hline
\end{tabular}

Linear regression analysis of traffic volumes and times of two scenarios were performed to determine the effect of infrastructural changes on the traffic characteristics (see table 2). The results prove that the traffic volume decreases and the auto time spent in the transport network is longer when the existing infrastructure of a transport network is improved. 
Analysis of the congested and unsafe segment in the street network (see figure $2 \mathrm{~b}$ ) was performed by applying the functional relation analysis. The features (values of the variables) of this section are as follows:

- $\quad$ traffic volume corresponds to the arterial street $\left(f_{31}\right)$;

- in some parts the cross-section corresponds to the (major) collector street $\left(f_{21}\right)$;

- density of intersections corresponds to collector street $\left(f_{24}\right)$;

- type of some intersections corresponds to the residential street $\left(f_{23}\right)$;

- $\quad$ access control is between the residential and collector street level $\left(f_{22}\right)$;

- infrastructure for pedestrians and cyclists corresponds to the collector street and is not sufficient $\left(f_{28}\right)$;

- $\quad$ police enforcement is very poor $\left(f_{42}\right)$.

As the result of modelling, there are relational failures, since $f_{11}=1, f_{12}=1$, $f_{13}=1$. These failures differ along the section due to different infrastructure and different usage. The results of improper interaction of functions are as follows: traffic conflicts, accidents and casualties, travel time, air and noise pollution, living comfort level, etc.

In practice on this section we have traffic jams, long travel time, high accident rate, high air pollution and unsatisfactory pedestrian and cyclist conditions. Relational failure takes place very often. The problem is that the degree of failure is unknown. There is only an idea about the output of the failure degree and the origin of failure.

\section{Discussions}

Topics for further discussions and model improvement:

- The value of $f_{1 i}=\left\{f_{2 i}, \ldots, f_{2 n}, f_{3 i}, \ldots, f_{3 n}, f_{4 i}, \ldots, f_{4 n}\right\}$, which represents sustainable conditions, is a matter of discussion. The major questions are: what should be the number of variables and what values generally represent $f_{1 i}$.

- The fine-tuning of values of $f_{1 i}$ is performed by experts due to the complexity of this variable. Such evaluation is quite subjective and is influenced by a human factor.

- Relational failures occur very often during modelling or making prognosis. Despite the question of composition of $f_{1 i}$, there is a need to evaluate the degree of relational failure. It should be useful both for model development as well as practical decisions to improve the situation on the road section.

It is considered that relations for sustainable safety can be successfully used for evaluation of development of a street network, for evaluation of projects for new constructions and improvements. 
636 The Sustainable City IV: Urban Regeneration and Sustainability

\section{References}

[1] Schermers, G., Vliet, P. Sustainable safety - a preventative road safety strategy for the future: $2^{\text {nd }}$ edition, Rotterdam, pp. 15-17, 2001.

www.swov.nl/en/publicaties/index.htm

[2] Hensher D. A., Button K. J. Handbook of transport modelling. Pergamon, p.91-110, 2005. 